\title{
"Jamás deja de ser entendido el orador que pronuncia criollamente". La disputa por la lengua: la pronunciación como marca de identidad nacional
}

\author{
"Jamás deja de ser entendido el orador \\ que pronuncia criollamente". \\ The dispute over language: Pronunciation \\ as a national identity mark
}

\author{
Esther Martínez Luna \\ Universidad Nacional Autónoma de México, \\ Instituto de Investigaciones Filológicas \\ mesther@unam.mx
}

RESUMEN: El objetivo de este artículo es analizar la larga polémica que, en torno a la pronunciación, como marca de identidad nacional, sostuvieron algunos letrados en las páginas del Diario de México. Jacobo de Villaurrutia, editor y colaborador del periódico, fue la voz más importante que condujo la polémica hacia una postura más abierta y menos normativa.

\author{
Palabras clave: \\ Ilustración; \\ identidad lingüística; \\ Jacobo de Villaurrutia; \\ polémicas letradas; \\ Diario de México; \\ Gazeta de Guatemala.
}

KEYWORDS:

Enlightment;

Linguistic identity; Jacobo de Villaurrutia; Controversial Discussions;

Diario de México;

Gazeta de Guatemala.
ABSTRACT: The objective of this article is to analyze the long polemic that surrounds pronunciation as a national identity mark, as some "hommes des lettres" maintained in the pages of the Diario de México. Jacobo de Villaurrutia, editor and collaborator of the newspaper, was the most important voice that led the controversy toward a more open and less normative position. 
Uno de los estudios que más interesan al hombre es el del idioma que se habla en su país natal. Su cultivo y perfección constituyen la base de todos los adelantamientos intelectuales. Se forman las cabezas por las lenguas.

ROUSSEAU

\section{Antecedentes}

Al hablar de reformas lingüísticas e identidad nacional durante el siglo XIX en Latinoamérica, inevitablemente surge el nombre del venezolano Andrés Bello, quien con su Gramática de la lengua castellana destinada al uso de los americanos ${ }^{1}$ sistematizó las inquietudes acerca de la lengua y la identidad. De la misma manera, cuando se quiere hablar del escritor moderno que mejor representa los inicios de la emancipación literaria y de nuestras sociedades americanas se menciona a José Joaquín Fernández de Lizardi. Sin embargo, poco se sabe o poco se dice acerca de los antecedentes o síntomas culturales que fueron marcando y allanando el camino para llegar al punto más alto donde ellos se encumbraron. Me refiero a que muchas ideas concretadas gracias a estos distinguidos hombres de letras encuentran su antecedente y se hallan desperdigadas en la prensa de los últimos lustros del setecientos o de los primeros años del siglo xIx; en particular aludo al primer cotidiano de la Nueva España, el Diario de México, y la Gazeta de Guatemala, espacios donde diversos hombres de letras se dieron a la tarea de reflexionar sobre la pronunciación de la lengua castellana, teniendo al criollo dominicano Jacobo de Villaurrutia a la cabeza de lo que Bello, apenas pocos años después de consumadas las independencias de Hispanoamérica, llevaría a la mesa de discusión. Así, el nombre del venezolano ha venido a enarbolar los principios lingüísticos y normativos de un proyecto de fuerte raigambre ilustrada. Por su parte, Villaurrutia, sin embargo, a pesar de su importante trayectoria como intelectual y fun-

1 Recordemos que el venezolano, durante su exilio en Londres, da a conocer en 1823 las "Indicaciones sobre la conveniencia de simplificar y uniformar la ortografía en América"; véanse sus Obras completas (Bello 1951). 
cionario crítico de la Corona, ha ocupado un lugar modesto dentro del entramado de los proyectos lingüísticos relacionados con un discurso caracterizado por una conciencia ideológica en busca de la emancipación, no obstante, su continuo interés y los debates que suscitó en la época.

Como bien sabemos, el Diario de México (1805-1817) fue el periódico que en los albores del siglo xIx practicó en sus páginas un periodismo de tipo ilustrado. Entre este tipo de prácticas ilustradas la polémica fue un importante recurso para mostrar la opinión de los criollos letrados que participaban de manera activa señalando lo que preocupaba e importaba a los miembros de la sociedad novohispana. Dentro de la amplia y variada gama de temas que se sometieron a discusión en todos los ámbitos del conocimiento, el referente a la lengua castellana y sus variadas pronunciaciones es ahora motivo de nuestra atención.

Apenas tenía unas cuantas semanas de estar en circulación el Diario de México, cuando el sábado 9 de noviembre de 1805 se publicó la carta de un lector que preguntaba al editor $y$, en consecuencia, a los lectores del Diario:

Señor diarista: pretendo saber por usted o por otro que lo sepa, ¿cuál es el motivo porque nosotros los criollos en general no pronunciamos con perfección nuestro idioma español?, ¿será porque nuestros padres no nos lo enseñan desde pequeñitos?, o iporque aunque queramos algunos hacer alarde de saber charlar, pronunciando las zetas, las ces y las elles, se nos murmura por nuestros mismos paisanos, atribuyéndonos a faramalla lo que debía ser una buena recomendación en un criollo? (Diario de México [en adelante DdeM], 1805a: 166).

Así, esta pregunta en apariencia tan sencilla o inocente fue el inicio de una larga, larga polémica que duró no semanas, no meses, sino años en las páginas de nuestro cotidiano. Esta carta firmada bajo el seudónimo de "El Criollo Mexicano" desató tal controversia que más de un letrado se interesó en hacer públicas sus críticas, cuestionamientos, reflexiones o simplemente exponer sus ideas en torno a la pronunciación del castellano que se hablaba en tierras americanas con respecto al castellano hablado en la península. El debate desplegó una pluralidad de opiniones y posturas que al ser estudiadas en su contexto nos devela la carga ideológica y 
política que iba más allá de pronunciar de tal o cual manera. Pero expliquemos en qué consistió esta larga polémica.

En las páginas del periódico se enfrentaron, esencialmente, dos posturas: una que consideraba que el castellano hablado por los criollos americanos tenía muchos vicios e incurría en abundantes faltas y errores que debían ser corregidos. Otra, que sostenía que el castellano hablado de manera distinta, y que presentaba variantes con respecto a la península era válida y debía respetarse, ya que el pronunciar de manera diferente en relación con los hablantes de la metrópoli no conducía a la falta de comunicación entre los hombres. ${ }^{2}$ Agreguemos que esta larga polémica no sólo se centró en la pronunciación, sino que abarcó un mayor espectro temático que incluyó la ortografía, la enseñanza de las primeras letras, el buen gusto, la pervivencia del latín —colateralmente las lenguas indígenas—, además de definir a los hablantes de uno y otro bando por su lugar de nacimiento:

- Mestrito (diminutivo que significa cariño) usted es un pedante ridículo que quiere que los crioyos [sic] hablen como gachupines.

- ¿A qué llama usted gachupines, a los españoles europeos?

- Sí señor.

- iCon que los andaluces, murcianos, valencianos son gachupines, no solamente los castellanos?

- A todos los que no son americanos llamamos gachupines.

- ¿Y qué, es defecto imitarlos en el habla?

2 Así argumentaba El Payo tierradentreño en las páginas del periódico: “¿Dígame señor diarista, perdonando al Tierradentreño, los idiomas no los creó Dios para que viviendo las gentes en sociedad se entendieran unas a otras? Me dirá usted que sí, pues bien, ¿nuestro lenguaje, el de las Andalucías y el de muchos lugares de España que no tienen la costumbre de pronunciar las letras dichas con el sonido que les es propio, no se entiende? Sí, y tanto que no es necesario preguntar qué acabó de decir aquél que habló; luego esto no es por defecto de lo hablado que no se entiende, sino porque en la primitiva quisieron dar aquel sonido a las letras y querer que esto se propagase, es más capricho que justicia./ En los sermones, discursos, informes y demás que tengo a usted dicho que he oído, han sido muchos producidos por científicos criollos, y he tenido la satisfacción de oírlos elogiar con las expresiones de: 'qué bien explica', 'qué claro habla', 'qué producciones tan enérgicas', 'qué instruido está', y nadie dijo no sabe hablar, a que se agrega (según mi sentir) ser muy dulce y clara la pronunciación del criollo con respecto al europeo, que con la dureza de las zz, no es tan perceptible al oído, al menos a mí me hiere más suave el órgano del oído, y con más suavidad el uno que el otro lenguaje" (1806d: 98, 99). 
- El idioma entre nosotros y ellos es uno mismo; pero el sonido de algunas letras nos distingue (DdeM,1805c: 273; subrayado mío).

Como se puede advertir en este diálogo, el enfrentamiento iniciaba por el lugar de nacimiento; así pues, se enfrentaban el bando de los llamados gachupines (españoles) contra el bando de los criollos (americanos). Un bando pedía respetar y preservar la norma castellana como la única legítima, mientras que el otro grupo exigía el respeto por la variedad.

Los letrados colaboradores del Diario, en su afán normativo dentro de las características del discurso ilustrado, discutieron y formularon hipótesis acerca de que el origen de una buena pronunciación estaba totalmente relacionada con tener una buena ortografía, pues el saber escribir conducía naturalmente a saber pronunciar y diferenciar los sonidos de ciertas consonantes como las zetas, ces, elles o eses. Estos hombres abrigaban la convicción de que entre la letra y el sonido había (o debería haber) una correspondencia perfecta, certeza que implicaba la primacía del sistema ortográfico sin ninguna consideración filológica o histórica.

Es verdad que muchos de mis paisanos, por miedo de la crítica e irrisión que se hace de los que pronuncian su idioma como deben, se abstienen de practicarlo; pero en mi opinión, aunque ésta es la causa en algunos sujetos de instrucción y cultura, en los demás es la ignorancia general que reina en punto de ortografía. ¿Cómo pues, sabrá pronunciar corazón con z, el que lo escribe con s, ni haIlazgo con II, si lo escribe con y? Sí señor diarista, usan tan indiferentemente de estas letras que es ilegible lo que escriben semejantes sujetos.

Alguno me dirá que sólo las mujeres y hombres de inferior clase ignoran la ortografía; pero no es así, pues aun algunos Letrados y Doctores padecen el mismo achaque. De todo lo cual infiero que para ocurrir a aquel proyecto de hablar bien es indispensable escribir del mismo modo; y si usted quiere poner el oportuno remedio, dígales con don Antonio Nebrija que "la buena pronunciación depende de la buena ortografía" (DdeM, 1806a: 106).

Sin embargo, este tipo de razonamientos, a pesar de lo contundente, no inmutaba ni convencía a ciertos criollos letrados que argumentaban que ellos escribían correctamente, ya que sabían diferenciar la escritura del habla de todos los días, pues una cosa era la palabra escrita y otra muy diferente, la palabra hablada. En consecuencia, proponían que en caso de 
duda, siempre se podía recurrir al Diccionario de la Lengua Castellana de la Real Academia para escribir correctamente. ${ }^{3}$ No obstante los desacuerdos en cuanto a la manera de pronunciar, el discurso de las diversas posturas entre criollos y españoles apelaba a un saber académico, letrado y normativo cuyos códigos conceptuales, abstractos y racionales incluso remitían a una tradición lingüística, al traer a la mesa de discusión al humanista Antonio de Nebrija, cuya gramática había gozado de gran reputación. Por tal motivo, el debate también se condujo a la importancia de la enseñanza de las primeras letras, donde para modificar los usos viciosos de la pronunciación americana era necesario que los niños aprendieran —-porque los adultos ya no tenían remedio- a leer y escribir con preceptores que pronunciaran el verdadero idioma patrio de los castellanos viejos, y de la misma manera indujeran a sus pupilos a practicar sonidos desconocidos o poco escuchados en su comunidad. En virtud de ello, podían auxiliarse "del alfabeto de la academia española, imponiendo bien a sus discípulos en dar exactamente a cada letra su propio sonido. Con esto, y con que también aprendan, lo que es cosa muy llana, la arreglada acentuación de las sílabas, no es menester más para que pronuncien perfectamente" (DdeM, 1806c: 439). Es así que los maestros o preceptores detentaban la autoridad para guiar la enseñanza y observar las normas de un saber institucionalizado y regulador de las leyes culturales y de la alfabetización en torno de la lengua, pues el aparato educativo representaba la defensa del sistema social y político. El Escuelero Tierradentro así nos lo hace saber:

Yo, señor, me hallaba en un pueblo enseñando primeras letras; lo diré más claro, era escuelero. Pero cuando me dediqué a este oficio fue en la inteligencia de que iba a enseñar a leer, hablar y escribir el propio idioma, que es decir, la gramática. Y como era necesario comenzar por el a b c, y éste lo sabía yo tan mal, traté de reformar en mí y en mis niños los defectos de la mala pronunciación, considerando que si pasan a la poesía y elocuencia serán éstas siempre imperfectas (DdeM, 1805b: 263).

3 El Diccionario había aparecido por vez primera unos pocos años antes, en 1780, y en 1803 ya tenía una cuarta edición. No sobra decir que, por su parte, el Diccionario de Autoridades (1726-1739) incluyó un apartado titulado "Orthographía", y Mateo Alemán publicó su Ortografía Castellana (1609), textos a los que también se aludía para su consulta. 
Los niños vendrían a ser los receptores de las convenciones más tradicionales de la lengua. Aprender a leer y escribir ocupaba una posición estratégica y definida en el centro de la educación civil, un ejercicio racional que cabe depurar intelectualmente y una facultad que constituye el tronco del árbol de la poesía (todo tipo de discursos orientados a suscitar la emoción estética) y de la elocuencia (todo tipo de discurso construido como sustento de la sociabilidad política del reino). Aunque como sabemos se trataba de un problema más complejo, que no se podía limitar por la supuesta adaptación a un modelo o sistema inamovible. ${ }^{4}$

Por otro lado, a lo largo de esta polémica, el único punto en el que sí Ilegaron a coincidir nuestros letrados fue al censurar los Ilamados "barbarismos" o "idiotismos" que utilizaba al hablar la gente "rústica", ya que su pronunciación corrompía el lenguaje; ejemplo de ello era el uso de palabras como "catasismo, prensipio, agüelito, juimos, vini, tráir, inorar, siudá" (DdeM, 1805c: 274), o señalando que "muchos indios (siendo difícil a esta nación la pronunciación de la $B, V, U, y$ D) aunque se críen y traten familiarmente con españoles largo tiempo dicen el pagre, la magre, por padre y madre, pentóra por ventura" (DdeM, 1806f: 321).

Ya se advierte que lo sustantivo de la discusión se centraba en la perfecta pronunciación castellana respecto de la distinción de ciertos sonidos consonánticos relacionados con el habla de la metrópoli, pues los hombres que estaban influidos por una pronunciación "grosera y rústica", no podían ser considerados para participar del debate, ya que pertenecían a "la plebe", un sector periférico de la sociedad que no tenía voz. A decir

4 Es importante consignar que, independientemente de la polémica que estudiamos, la preocupación por la enseñanza de las primeras letras fue un punto sustantivo en la sociedad de la época; pues era importante saber escribir con una "correcta ortografía" o mejor dicho con las grafías que exigían la reglamentación del periodo. Esta reglamentación en especial representó un problema para los hombres que desempeñaban tareas públicas, como los escribanos, los editores y tipógrafos. Asimismo, la enseñanza de la gramática, a partir de 1780, tanto en la península como en la Nueva España se convirtió en algo prioritario, pues solía ser común publicar anuncios en la prensa de profesores que consignaban la utilidad de aprender gramática y retórica. Entre los profesores que destacaban para impartir dichas disciplinas se encontraban José Vélez, Fernando Velázquez de Lorea y Anselmo del Río "preceptores [que] por su eficaz aplicación merecen ciertamente mucho agradecimiento y que los elogie una pluma superior" (DdeM, 1806b: 371). 
de los polemistas, estos desclasados sí representaban lo distante y ajeno del buen castellano. No olvidemos que estas discusiones atañen a ciertas minorías letradas ajenas y en absoluto interesadas en identificarse con los colectivos iletrados, mestizos y mucho menos con los grupos indios. Estamos hablando de que el debate tiene lugar entre individuos letrados y conscientes del lugar que ocupan en la esfera político social y su rivalidad es con los peninsulares o con ciertos criollos aún muy vinculados con la metrópoli por la jerarquía burocrática que detentan.

De esta manera se ignoraban las voces, palabras o sonidos que evidenciaban una fuerte influencia de las lenguas indígenas como continuaría sucediendo años más tarde en las discusiones entre conservadores y liberales, quienes no contemplarían, ni por asomo, incorporar a las lenguas vernáculas pues, por paradójico que parezca, éstas se hallaban fuera de cualquier proyecto nacionalista; además de que a dichas lenguas se les relacionaba con el mundo rural y, en consecuencia, con el atraso. Saber alguna lengua indígena no confería ningún estatus ni promoción social dentro del discurso dominante.

Vale la pena consignar que durante el siglo XIX se llegó a hablar de ciertas letras-grafías más que de lenguas indígenas; por ejemplo, se buscó dar prioridad, dentro de la escritura, a la X sobre la J para mostrar simbólicamente una marca de identidad. ${ }^{5}$ En contraste, podemos señalar cómo con

5 La Real Academia Española había dictaminado unificar la J sobre la X, pero esta regla fue muy pronto rechazada por parte de algunos personajes importantes; tal es el caso de fray Servando Teresa de Mier, quien, en su Carta de despedida a los mexicanos, en 1821, señalaba: "Yo profesé la lengua española en París y Lisboa, he meditado mucho sobre ella, he llegado a fijar su prosodia, y tengo muchas razones que oponer contra esas novedades inútiles, y especialmente contra la extensión que quiere darse a la $j$ tan fea en sus pronunciación como en su figura, tan desconocida de los latinos como de los antiguos españoles, que nos dificultará el aprendizaje del latín y de sus dialectos europeos. En cuanto tenga lugar expondré mis razones./ Como quiera que sea, esta carta se reduce a suplicar por despedida a mis paisanos anahuacenses recusen la supresión de la $x$ en los nombres mexicanos o aztecas que nos quedan de los lugares, y especialmente de México, porque sería acabar de estropearlos. Y es grande lástima, porque todos son significativos, y en su significado topográficos, estadísticos, o históricos. [...] En todo caso, paisanos míos, sigamos a escribírlo con $x$, o para llegar con el tiempo, si la nueva ortografía predomina, a pronunciar como se debe éste y los demás términos mexicanos, o para no echar en olvido enteramente una de nuestras mayores glorias. Si, México con x suave como lo pronuncian los indios significa: donde está o es adorado Cristo, y mexicanos es lo mismo que cristianos" (Mier 1821: s/p). Si bien, por 
el latín sucedía lo contrario pues, si bien ya comenzaba a estar en desuso, esta lengua romance revestía de prestigio a quien la utilizaba como paradigma de erudición y modelo de imitación.

Hasta aquí, a grandes rasgos, los puntos más representativos que conformaron la polémica.

\section{Identidades}

[...] el señor Payo dice muy bien: jamás deja de ser entendido el orador que pronuncia criollamente.

Como se advierte, estas comunidades en pugna escriben y envían sus cartas al Diario de México para incluirse en la vida social y cultural de los albores del siglo xix. De tal manera que el problema de la lengua y la pronunciación no se limitará únicamente al terreno especializado y de disputas eruditas, sino que comenzará a generar un distintivo de proyección cultural y un cariz de identidad nacional, político y social. Señalemos que estas discusiones tienen lugar apenas unos cuantos años antes de que dé inicio la guerra de Independencia y estos ríspidos diálogos ya nos muestran la temperatura del ambiente político que reinaba en la Nueva España. Es así que en algún sentido respetar la normatividad lingüística, cultivar y obedecer el sistema de códigos de la península, significaba acatar la autoridad del orden virreinal y metropolitano.

El pretender que los criollos hablaran como los gachupines evidenciaba simbólicamente el control y la autoafirmación de la metrópoli para continuar manteniendo el orden y el poder. ${ }^{6}$ Por ello, un grupo significativo de españoles americanos se esforzaba por una pronunciación castiza

una parte se defendía la utilización de ciertas grafías, por la otra, era muy común ver la construcción de frases con giros peninsulares, por ejemplo, la dijo, y otras muchas vacilaciones normativas en el espacio textual del Diario de México. Todo este tipo de vacilaciones alimentó la discusión entre los letrados y su consecuente identidad.

6 “iQué gloria sería para la N[ueva] E[spaña] igualarse en esta materia con la Metrópoli, y que resonara en sus distritos el agradable sonido de la verdadera lengua castellana, oyendo pronunciarla a los españoles americanos con toda la excelencia de que es susceptible, y dentro de muy pocos años, a lo menos en los que ahora empiezan a vivir!" (DdeM, 1805a: 166). 
("la única correcta"), pues estaban convencidos de que esta distinción les ayudaría a obtener mejores puestos dentro de la pirámide políticoburocrática. Sin embargo, los resultados no siempre fueron los deseados porque se incurría en una pronunciación afectada e incorrecta que sólo causaba la burla y el rubor de más de uno que los escuchaba diferenciar mal los sonidos de las Z, C y la S, lo que provocaba que pronunciaran: Paztel, Zeñora, Paizanos, Prenza (DdeM, 1806g: 384). Seguramente debió ocurrir a menudo este tipo de pifias pues en las páginas del Diario de México con cierta sorna e ironía se hizo referencia a quienes buscaban distinguirse con este supuesto prestigio lingüístico. Por ejemplo, la primera dama del teatro mexicano, Luz Vallecillo, "actriz de un mérito capaz de hacerla lucir en los [tablados] de Europa" (DdeM, 1807b: 23), sube a los escenarios teatrales de la ciudad capital del virreinato para hacer gala, junto con sus dotes interpretativas, de una flamante y orgullosa pronunciación castellana digna de admiración a pesar de que no sea de extrañar que se le escapen de la boca algunos rasgos de la articulación verbal propia de quienes, como ella, han nacido en México. Doña Luz se presenta luego de haber estado en La Habana "luciendo su papel con mejor aire y más expresiva en la acción, y pronunciando bien la $z$, la c y la II, no siendo de extrañar que se le escape una u otra, porque un año no es bastante tiempo para destruir enteramente un hábito de muchos" (23).

Los editores del Diario de México escriben este elogio con el propósito de resarcir a la primera actriz de la burla que a sus costillas había gastado Pepita Gamunz, seudónimo de José Mariano Guzmán, quien así caracterizaba a su "amiguita": "La pobrecita, antes de ahora, era amable, tenía una conversación graciosa y divertida porque Dios la dotó de talento, claridad, expresión y pronunciaba con mucha naturalidad, sin vulgarismos ni disparates" (DdeM, 1807a: 18). Pero he aquí que la primera actriz, lectora consuetudinaria del Diario de México, tomó el partido de quienes en esas páginas alegaban a favor de la conveniencia de pronunciar la lengua patria, la lengua de los españoles de América con base en la norma de Castilla. En consecuencia, el satírico travestido afirmaba: "a mi amiga [...] se le trastornó la cabeza y de la noche a la mañana se nos ha vuelto una gachupina muy refinada" (18-19). En seguida se desarrolla la materia de la sátira que concluye en cuanto al motivo de la actriz: "No parece sino que 
pronuncia con dos zz corazzón, y que después de la /l siempre pone una $i$ para decirnos ellia, halliazgo, etcétera, y en cuanto a la c y $s$, de esto no se hable" (19). ${ }^{7}$

Por otro lado, también estaban los criollos que defendían su identidad ligada a una pronunciación más acorde a su nueva tierra y a los requerimientos sociales con los que se relacionaban y convivían; una pronunciación asociada a una lengua que se modificaba o distorsionaba día con día hacia registros menos rígidos que los dictados por España. Sin duda, las reformas borbónicas incidieron en problematizar acerca de la identidad y el entorno en el cual se habían educado estos criollos letrados que buscaban la transformación y la distancia respecto de Europa.

Sea lo que fuere, yo tengo por imprudencia y pedantería, la de aquellos que, apartándose de una costumbre casi universal y antiquísima, quieren con su modo de pronunciar trastornar la constitución nacional de nuestro idioma. Ellos mismos se hacen violencia para vencer la naturaleza en una cosa que nada tiene de vicio. ¡Ojalá y así la hicieran para vencer sus pasiones, y como quieren dar ejemplo de buena locución, lo dieran de actos virtuosos! Censuran ellos mismos nuestra pronunciación criolla, tratándonos a los que acostumbramos con la expresión de tecomates. ¡No ven pues, que ellos mismos se envilecen con esto! Dan a entender que es vil y despreciable el criollismo; y no pudiendo desnudarse de la cualidad de criollos, como que se avergüenzan de serlo, se despojan del más perceptible distintivo, cual es el de la pronunciación (DdeM, 1806f: 321-322).

Estos debates sobre la lengua se asocian a lo que podríamos llamar prestigio social al hablar de una manera específica y no de otra. Los distintos letrados que participaron bajo diferentes seudónimos en la polémica ("El Criollo mexicano", "El Escuelero", "El Escuelero Tierradentro", "L.P.", "El Criollo pueblano", "El Criollo otomí", "El Payo tierradentreño", "El Criollo refinado", "El Criollo no refinado" y "Pepita Gamunz") tienen la certeza de que su disputa es entre pares a los que interesa y atañe este tipo de discusión lingüística por el lugar que ocupan dentro de la sociedad

7 En esta sátira y en su comentario crítico al pie de página se encuentran contenidos e ilustrados los términos de una discusión que reclutó la participación de Jacobo de Villaurrutia de manera muy activa, pues como sabemos fue el promotor, fundamental, de la polémica. 
novohispana, además de que los ratifica dentro de un status quo, pues la forma de utilizar la lengua los representa como sujetos de acción que se comportan en concordancia con sus pensamientos. El criollo educado en las ciudades del virreinato de la Nueva España con tradiciones e instituciones culturales bien estructuradas se considera un depositario de la lengua española cuyos códigos conceptuales, abstractos y racionales ha de conocer conscientemente, cultivar, obedecer y formalizar. La situación identitaria de este letrado descansa en la lengua entendida como un sistema de códigos racionales susceptible de ser reducido al entendimiento humano y, en consecuencia, al aprendizaje y a la enseñanza.

En consecuencia, fue una discusión que bajo el velo de la lengua nos evidencia las fuertes tensiones ideológicas que existían entre los criollos. En virtud de ello, podemos decir que la lengua española y su norma se convirtieron en un símbolo identitario de una sociedad que ya mostraba claros signos de querer modificarse. Por supuesto, estos signos de cambio o restructuración eran producto de un marco histórico e ideológico cuyas ideas ilustradas enmascaraban un afán cientificista, donde lo que supuestamente importaba era la correcta ejecución de una lengua y su apego a una normatividad a cuya reglamentación había que ceñirse. La institución de la lengua sería un terreno especialmente cultivado por estos letrados no sólo como materia de sus conocimientos eruditos y especializados, sino como proyección cultural de su identidad política.

Como decía al principio de este texto, resulta curioso que la preocupación de la lengua y la identidad sólo se ubique años después de las guerras de emancipación continentales como hechos aislados y privativos al discurso que enarboló Andrés Bello. ${ }^{8}$ Sin afán de quitarle mérito al venezolano, simplemente maticemos que, algunos lustros antes, los letrados novohispanos ya discutían acerca de la pronunciación, la gramática, su

8 Incluso, es moneda común leer aseveraciones a propósito de los debates sobre la lengua sólo tienen lugar en la segunda mitad del siglo xIX. Apuntemos que Chile destaca dentro de los países hispanoamericanos como el que ha abordado más ampliamente el tema, en particular el debate de la ortografía. Miguel Rodríguez Macías señala que "el prologuista de Bello, Ángel Rosenblat, indica que estas ideas circularon a lo largo del siglo xIx en Hispanoamérica, influenciando círculos literarios y lingüísticos en Venezuela, y que fueron adoptadas seguramente en Ecuador, Colombia y Nicaragua" (2004: 102). 
enseñanza, el léxico, la literatura, el buen gusto, como un problema de identidad y de creación de una norma americana.

También consideremos que años antes — a pesar de que el ámbito oral se dice era diferente del escrito-, una parte de la poesía que se publicó en las páginas de Diario de México apelaba a un vocabulario rico en palabras que tenían que ver con la flora y fauna de la región, un léxico americano que se adaptaba a la tradición grecolatina (por ejemplo, al escribir una anacreóntica al pulque y no al vino, una oda al cenzontle y no al canario —o en el caso argentino la oda al majestuoso río Paraná de José Manuel Lavardén); fue tal la cantidad de textos literarios que recurrieron a este tipo de léxico que es digno de señalarse. A este vocabulario, como sabemos, después recurrirían los románticos para exaltar la naturaleza y el paisaje vernáculos.

Esta identidad "americana" por medio de la lengua fue una búsqueda por demostrar que se tenían rasgos particulares de carácter cultural, social, etnográfico y lingüístico que hacía a los criollos ser diferentes respecto de los europeos, en consecuencia, había que compartir este importante patrimonio y convertirlo en norma.

He visto [...] y veo también que los aldeanos hablan de un modo, de otro los plebeyos y los civilizados de otro; que lo mismo es en España, y allí se distinguen los andaluces de los vizcaínos, y los dos de los montañeses, gallegos, etcétera; es decir, que cada nación tiene su modo característico que la distingue y que por lo mismo a la nuestra no se le debe reprobar el suyo, porque no se parece al que se usa en Madrid, ni hay tampoco un fundamento racional para ello (DdeM, 1807a: 22).

Es muy antigua la época (porque no encuentro entre los más ancianos quién de su principio me dé razón) del uso y diferencia que hay de la pronunciación del idioma castellano en nuestra América, y la del mismo en los reinos europeos de España. Lo principal de esta diferencia consiste en que los nativos de aquellos países a quienes conocemos bajo la denominación de gachupines pronuncian la $S$ forzando la expulsión del aire entre los dientes; y nosotros los criollos la pronunciamos expeliéndolo suavemente entre la lengua y el paladar (DdeM, 1806e: 315).

Los textos que se intercambian a lo largo de esta polémica son un rico banquete para el análisis retórico y literario, ya que sus contrincantes ha- 
cen gala de un profundo conocimiento de las herramientas de la argumentación. Así advertimos que los textos están permeados de una aguda ironía que se combina con los rasgos esenciales de la sátira ilustrada. ${ }^{9}$ Los debatientes en apariencia quieren hacernos creer que defienden una postura cuando en realidad la están atacando, tal es el caso de El Escuelero de Tierradentro, quien afirma compartir las preguntas y posturas de El Criollo Mexicano, y pone en voz de su alumno más avezado lo que él supuestamente rechaza; pero en realidad, al reproducir ampliamente el diálogo que sostuvo con su pupilo, sabemos que su simpatía y postura se dirigen por otros caminos, es decir, por la pronunciación americana. ${ }^{10}$

En estos ríspidos intercambios encontramos matices que enriquecen las opiniones expresadas por los diversos actores. A riesgo de ser inexacta, me atrevo a conjeturar que no sería raro que algún letrado haya utilizado más de un seudónimo para crear contrapuntos a su propia opinión, utilizando como recursos la ironía aunada a un tono picoso y el sarcasmo para ganar adeptos y descalificar, en apariencia, la pronunciación americana.

Y ¿qué decir de la postura del editor del periódico, quien seguramente estuvo escondido bajo alguno de los seudónimos? No olvidemos que uno de los editores del Diario de México fue Jacobo de Villaurrutia, quien pretendía imponer el uso fonético de la ortografía.

\section{Jacobo de Villaurrutia y sus tempranas reformas ortográficas}

La perfección de la ortografía consiste en que siempre vayan acordes la escritura y la pronunciación.

Sabemos que las páginas del Diario de México fueron las principales aliadas de Jacobo de Villaurrutia para insistir en la correspondencia entre pronunciación y ortografía. Sin embargo, sus primeros cuestionamientos

9 Para mayor información con respecto a la sátira ilustrada en el discurso periodístico del Diario de México puede consultarse Martínez Luna (2011: 69-80).

10 La respuesta de El Escuelero Tierradentro consta de tres extensas entregas. El diálogo representa el mejor ejemplo de las dos posturas respecto de la pronunciación que conducirán toda la larga polémica, aun con actores distintos a los que iniciaron el debate. 
sobre el tema se encuentran en las páginas de la Gazeta de Guatemala, donde también fuera editor. ${ }^{11}$

El inicio de sus preocupaciones tiene lugar el lunes 2 de marzo de 1801 cuando en la Gazeta publica el texto titulado "Ortografía", donde se da a la tarea de señalar los desacuerdos que tiene con las reglas ortográficas que la Academia había impuesto. En sus "Observaciones sobre la ortografía de la Academia Española", Villaurrutia comienza por reconocer ciertas modificaciones que ayudan a la escritura, pero en seguida, contundente, afirma:

debemos confesar que todavía estamos necesitados de una ortografía más fácil y más clara; de una ortografía fundada, si es posible, en una sola regla, que, abrazando todos los casos, sin la menor excepción, no deje libertad de escribir una misma voz con diversidad de letras; de una ortografía, de la cual los jóvenes, al salir de la escuela de primeras letras, se hallen perfectamente instruidos, sin que les reste nada que saber en cuanto a esto (Gazeta de Guatemala, 1801: 405; cursivas mías).

La idea que promueve es la simplificación de los sonidos, es decir que "siempre vayan exactamente acordes a la escritura y la pronunciación" (406). Para ello, es menester reducir el número de letras que tengan un sonido similar como la C, Q, K, J, G, S, Z, C, pues de esta manera se evitará no sólo escribir una palabra de manera diferente sino pronunciarla de manera diversa. Villaurrutia afirma que la supuesta riqueza y variedad de grafías sólo conducen a la confusión, pues los "usos comunes y cons-

11 Si bien la Gazeta de Guatemala apareció en 1729 y ocupó el cuarto lugar de las publicaciones en la América española, nosotros hacemos referencia a la Gazeta de Guatemala en su tercera época (1797-1807) dirigida por Jacobo de Villaurrutia, quien logró que la publicación desempeñara un importante papel respecto de las anteriores, ya que incluyó y promovió en sus páginas temas tanto de carácter científico, económico, comercial, como cultural y literario que posicionaron al impreso dentro de los debates más importantes de la época. Otro punto a destacar es que pocos años antes, en 1795, Villaurrutia había fundado la Sociedad Económica de Amigos del País, en consecuencia, sus relaciones con importantes hombres de letras le sirvieron para incorporarlos a la discusión y crear redes sólidas al incluirlos como colaboradores y suscriptores del impreso guatemalteco. De más está decir que pronto la publicación se volvió crítica y cuestionó más de un proyecto o las ideas de la Corona, situándolo como uno de los periódicos más importantes de la América central. Cfr. Poupeney Hart (2010) y Hernández Pérez (2015). 
tantes" en el español no son del todo ciertos porque hay más excepciones que normas, aunque la Academia piense lo opuesto. ${ }^{12}$ En este sentido, sus reflexiones se extienden hasta Du Marsais ${ }^{13}$ y por supuesto al concepto fonetista de Quintiliano:

Por lo que a mí me toca — dice Quintiliano—, a menos que un uso bien constante no ordene lo contrario, creo que cada palabra se debe escribir como se pronuncia, porque tal es el destino de las letras. Ellas deben conservar la pronunciación de las palabras. Es un depósito que deben volver a los que leen, de suerte que deben ser la señal de lo que se ha de pronunciar cuando se lee... (Gazeta de Guatemala, 1802: 4; cursivas mías).

En este sentido, su postura se aleja del discurso conservador y normativo que a la Corona le importaba tanto, pues en gran medida la unificación y control de sus reinos dependía de una sola identidad bajo el dominio de la lengua. Estamos a una década de la guerra de emancipación, pero los cuestionamientos a la metrópoli ya están presentes, paradójicamente, en boca de uno de sus funcionarios. Se podría incluso hablar de una norma criolla que busca un sitio hegemónico para trazar su propia fisonomía.

Jacobo de Villaurrutia, consumada la Independencia de México, continuó con sus empeños reformadores, prueba de ello es el largo texto publicado en el periódico de la masonería escocesa de Lucas Alamán, El Sol; nuestro letrado, bajo el seudónimo de NN., responde de manera incidental a las propuestas que había publicado Bello, en el mismo periódico. ${ }^{14}$

12 "La empresa de fijar la ortografía de la lengua castellana en una forma clara, sencilla, invariable, empresa que la Academia gradúa de ardua y difícil, creemos, nosotros, por el contrario, que es una empresa facilísima; y que si, como dice la misma Academia, y lo vemos todos con dolor, no se logró hasta ahora, fue por no haberse apreciado según su mérito las luces que autores de buen sentido esparcieron sobre tal objeto" (Gazeta de Guatemala, 1801: 406).

13 Es pertinente señalar que la figura de Du Marsais representa la visión "sensoempirista" de los gramáticos de la época, cuyo método era sustancial para el estudio del aprendizaje del latín o de lenguas modernas como el francés, el español y el portugués. Para una visión más amplia con respecto a la enseñanza de las primeras letras en los círculos jesuíticos, el método "port-royalista", así como la postura de las diferentes órdenes religiosas, véase Espino Martín (2018: 371-394).

14 Villaurrutia publica un largo texto, escrito con la ortografía que consideraba debía utilizarse, insiste en las ideas ya conocidas, años antes, de simplificar ciertos grupos consonánticos: "Todos los que an escrito antigua, y modernamente de la ma- 
Años más tarde, como sabemos y se ha documentado ampliamente, Domingo F. Sarmiento y Andrés Bello entablarán un prolijo debate en torno a la identidad lingüística de los países americanos. En cuanto a los discursos que abanderaron estos dos importantes letrados, sin duda, Jacobo de Villaurrutia tendría mayor afinidad con Sarmiento, pues el argentino tuvo una postura que defendía el uso de un español americano más flexible y abierto a los usos y costumbres de nuestra idiosincrasia, con giros y modismos del pueblo de donde habían emanado. Para Sarmiento, el uso cotidiano de la palabra se sobreponía a la enseñanza de la gramática porque América tenía su pronunciación, su entonación y su vocabulario. ${ }^{15}$

\section{Comentarios finales}

Si bien Villaurrutia utilizó la Gazeta de Guatemala de palestra para divulgar sus preocupaciones sobre la lengua, el Diario de México fue el espacio textual que aprovechó más ampliamente para exponer que la naturaleza de la discusión no era exclusivamente erudita o de carácter científico, sino que afectaba y daba sentido a tensiones relativas a la identidad histórica y cultural de cierto grupo letrado interesado en hacer de este asunto materia del debate público. Para explicar y persuadir a sus contemporáneos, Villaurrutia recurrió al igual que sus cofrades, al uso de diversos seudónimos con la intención de difundir distintas posturas, en ocasiones incluso contrarias, que produjeran contrapuntos en el debate. En este tenor, los registros que se recrearon en las páginas del periódico tuvieron tesituras que migraban de voces serias, solemnes, casi eruditas,

teria, están conformes en los prinzipios, y todos varian en aczidentes. Para uniformar la escritura, fijando el alfabeto con los signos nezesarios para espresar los sonidos de nuestro idioma, y escluyendo los superfluos, ó eqivocos, se debe azer por un cuerpo literario, como la academia de la lengua castellana, porqe si no, serian interminables las disputas y costaria mucho llegar al fin. [...] Me consuelo con la fundada esperanza de qe Mejico tenga la gloria de perfeczionar el alfabeto, y silabário castellano, y de mejorar mucho el diczionario de la academia española. Para ello creo qe contribuirán vds. como procurará azerlo en la parte qe pueda su servidor" (1824: 4, respetamos la redacción original).

15 En palabras del propio Sarmiento: "porque es ridículo estar usando la ortografía de una nación que pronuncia las palabras de distinto modo a nosotros, y esto precisamente en las letras cuyo uso es más difícil y nos llena de embarazos" (2002: 10). 
a otras cuyas expresiones eran más ligeras, más irónicas y desenfadadas, pero siempre su objetivo era convencer para ganar la contienda. Los seudónimos se convirtieron así en máscaras ficcionales de los contendientes para, incluso, jugar con la voz de sectores ajenos por completo al mundo letrado como los Ilamados Payos a quienes no se les concedía autoridad dentro de las redes académicas y eruditas de la ciudad. En consecuencia, al recurrir a un vasto número de voces ficcionales, sobre un mismo tema, los polemistas sembraban el germen de la duda respecto de las posturas de uno y otro bando al crear una polifonía de puntos de vista. En virtud de ello, los textos publicados no sólo se limitaron a estar escritos en prosa, sino que también se escribieron composiciones poéticas, entre fábulas, romances, sonetos, epigramas que aludieron al tema para contribuir a ampliar y sustentar el debate.

Esta larga polémica fue un claro reflejo de las preocupaciones de ciertas comunidades letradas que buscaban sancionar su postura respecto de las diversas maneras en que se manifestaba la escritura, el habla, la lectura, la educación, la poesía, etcétera. A pesar de toda la complejidad conceptual del debate, los participantes no olvidaron el carácter didáctico y pragmático que debían tener sus intervenciones. Su conversación fue un diálogo ríspido y a la vez jocoso, cuyos actores iban tomando su turno de acuerdo con la temporalidad en que habían enviado sus textos al Diario, pero también la publicación de sus cartas estuvo determinada por el espacio que decidían los propios editores del periódico. Dar un lugar preferente en la disposición material del impreso podía depender de la postura con la que más simpatizaban los responsables del periódico. Agreguemos, además, la utilización de notas a pie de página para descalificar o sancionar la contribución que se estaba publicando.

Finalmente, en los tempranos años del siglo XIX, Jacobo de Villaurrutia con su temperamento controvertible fue la voz hegemónica que señaló la existencia de una pronunciación diferente a la peninsular. Su empeño fue mostrar que existía una distancia con respecto de la metrópoli en más de un aspecto. El ser un criollo acaudalado depositario de una amplia cultura ilustrada y animador de importantes proyectos culturales contribuyó a que sus inquietudes fueran escuchadas en ámbitos restringidos sólo a los peninsulares. Él —junto con otros letrados- hizo del Diario de México 
un espacio para expresar sus desacuerdos con el orden vigente y difundir una nueva manera de pensar la realidad cultural, social e ideológica. Su persistente participación conformó una comunidad con cierta marca identitaria que respondía a las preocupaciones e inquietudes que como gremio exigían para construir una nueva sociedad.

\section{Bibliografía}

Bello, Andrés. Obras completas, vol. V. Estudios gramaticales. Caracas: Ministerio de Educación, 1951.

Bello, Andrés. Gramática de la lengua castellana destinada al uso de los americanos. Ramón Trujillo (ed.). Tenerife: Instituto Universitario de Lingüística Andrés Bello / Cabildo Insular de Tenerife, 1981.

Diario de MéxiCo. Diario de México, núm. 40, 1805a: 166.

Diario de México. Diario de México, núm. 64, 1805b: 263.

Diario de México. Diario de México, núm. 65, 1805c: 273-274.

Diario de México. Diario de México, núm. 119, 1806a: 106.

Diario de México. Diario de México, núm. 185, 1806b: 371.

Diario de México. Diario de México, núm. 202, 1806c: 439.

Diario de México. Diario de México, núm. 236, 1806d: 98-99.

Diario de México. Diario de México, núm. 289, 1806e: 315.

Diario de México. Diario de México, núm. 291, 1806f: 321-322.

Diario de México. Diario de México, núm. 429, 1806g: 384.

Diario de México. Diario de México, núm. 706, 1807a: 18-20.

Diario de México. Diario de México, núm. 707, 1807b: 23.

ESPINO MARTíN, JAVIER. "La recepción ideológica de las lenguas clásicas en la primera mitad del siglo XIX mexicano: conservadores y liberales", en Dimensiones de la cultura literaria en México (1800-1850). Modelos de sociabilidad, materialidades, géneros y tradiciones intelectuales. Esther Martínez Luna (coord.). México: Universidad Nacional Autónoma de México / Coordinación de Humanidades / Instituto de Investigaciones Filológicas / Instituto de Investigaciones Bibliográficas / Facultad de Filosofía y Letras, 2018. 371-394.

García MARTín, José María. "Revisión de algunas ideas sobre política e ideología lingüística en el siglo XVIII español", en Cuadernos de Ilustración y Romanticismo. Revista digital del Grupo de Estudios del Siglo XVIII, 17 (2011). Artículo en línea disponible en: <http://revistas.uca.es/index.php/cir/article/view/1580>.

Gazeta de Guatemala. Gazeta de Guatemala, núm. 241, 1802: 4.

Hernández Pérez, José Santos. La Gaceta de Guatemala: un espacio para la difusión del conocimiento científico (1797-1804). México: Universidad Nacional Autónoma de México / Centro de Investigaciones sobre América Latina y el Caribe, 2015.

Martínez LunA, Esther. El debate literario en el Diario de México (1805-1812). México: Universidad Nacional Autónoma de México / Instituto de Investigaciones Filológicas, 2011. 
Mier, fray Servando Teresa de. Carta de despedida a los mexicanos (1821). En línea disponible en: <http:/www.cervantesvirtual.com/obra-visor/carta-dedespedida-a-los-mexicanos-1821--0/html/7d9d3ffa-43c0-431e-bc3e-fad85966e30a_1.html> [consultado el 15 de febrero de 2019].

POUPENEY HART, CATHERINE. "Entre gaceta y 'espectador': avatares de la prensa antigua en América Central", en Cuadernos de Ilustración y Romanticismo. Revista digital del Grupo de Estudios del Siglo XVIII, 16 (2010). Artículo en línea disponible en: <http://revistas.uca.es/index.php/cir/article/view/195/193>.

Rodríguez Macías, Miguel. "'El idioma entre nosotros y eyos...': los debates sobre la ortografía de ambos lados del Atlántico en la primera mitad del siglo XIX", en Boletín del Instituto de Investigaciones Bibliográficas. Nueva época. México, vol. IX-1 y 2 (primero y segundo semestres 2004): 99-125.

SARmiento, Domingo F. Obras selectas. Madrid: Espasa-Calpe, 2002.

Villaurrutia, JACOBO DE. El Sol, núm. 397 (15 de julio de 1824): 4.

Villaurrutia, JaCobo DE. "Observación sobre la ortografía de la Academia Española", en Gazeta de Guatemala, núm. 193, 1801: 405-406.

ESTHER MARTÍNEZ LUNA

Doctora en Letras por la Facultad de Filosofía y Letras de la UNAM. Investigadora de tiempo completo del Centro de Estudios Literarios del Instituto de Investigaciones Filológicas. Miembro del Sistema Nacional de Investigadores y profesora de Literatura mexicana de los siglos XIX y XX en la Facultad de Filosofía y Letras.

Sus publicaciones, tanto nacionales como internacionales, se relacionan con la historia de la prensa y el mundo cultural y literario de finales del siglo XVIII y el siglo XIX. Entre sus libros podemos destacar: Bicentenario del Diario de México. Los albores de la cultura letrada en el México independiente (editora, 2009). A B C Diario de México: un acercamiento (2009). El debate literario en el Diario de México 1805-1812. Estudio, selección, edición y anotación (2011). Vicente Riva Palacio: Magistrado de la República Literaria. Una antología General. Estudio preliminar, selección y cronología. México: Fondo de Cultura Económica / Fundación para las Letras Mexicanas / Universidad Nacional Autónoma de México, 2012. Una selva tan infinita: la novela corta en México (18722011). 2 vols. Edición de Gustavo Jiménez, Gabriel Enríquez Hernández, Esther Martínez Luna, Salvador Tovar 
Mendoza y Raquel Velasco. México: Coordinación de Difusión Cultural / Dirección de Literatura / Universidad Nacional Autónoma de México / Fundación para las Letras Mexicanas, 2012. Una selva tan infinita. La novela corta en México (1891-2014), vol. 3. Gustavo Jiménez, coordinador. Edición de Gabriel Enríquez Hernández, Esther Martínez Luna y Raquel Velasco. México: Coordinación de Difusión Cultural / Dirección de Literatura / Universidad Nacional Autónoma de México / Fundación para las Letras Mexicanas, 2015. 